\title{
Gastric Inflammatory Myofibroblastic Tumor
}

National Cancer Institute

\section{Source}

National Cancer Institute. Gastric Inflammatory Myofibroblastic Tumor. NCI Thesaurus.

Code C7022.

A multinodular intermediate fibroblastic neoplasm arising from the stomach. It is

characterized by the presence of spindle-shaped fibroblasts and myofibroblasts, and a

chronic inflammatory infiltrate composed of eosinophils, lymphocytes and plasma cells. 